\title{
PACAP in the BNST Produces Anorexia and Weight Loss in Male and Female Rats
}

\author{
Margaret Kocho-Schellenberg', Kimberly R Lezak', Olivia M Harris', Erin Roelke', Niklas Gick', \\ Inyop Choi', Shaquille Edwards', Emily Wasserman', Donna J Toufexis', Karen M Braas'2, Victor May ${ }^{2}$ and \\ Sayamwong E Hammack*,1
}

'Department of Psychology, University of Vermont, Burlington, USA; ${ }^{2}$ Department of Neurological Sciences, University of Vermont College of Medicine, Burlington, USA

\begin{abstract}
Recent gene association studies have implicated pituitary adenylate cyclase-activating peptide (PACAP) systems in several psychiatric disorders associated with stressor exposure, and we have argued that many of the behavioral consequences of repeated stressor exposure may depend on the expression of PACAP in the bed nucleus of the stria terminalis (BNST). One behavioral consequence of the activation of stress systems can be anorexia and subsequent weight loss, and both the activation of central PACAP systems as well as neuronal activity in the BNST have also been associated with anorexic states in rodents. Hence, we investigated the regulation of food and water intake and weight loss following BNST PACAP infusion. BNST PACAP38 dose-dependently decreased body weight, as well as food and water intake in the first $24 \mathrm{~h}$ following infusion. Because different BNST subregions differentially regulate stress responding, we further examined the effects of PACAP38 in either the anterior or posterior BNST. Anterior BNST PACAP38 infusion did not alter weight gain, whereas posterior PACAP38 infusion resulted in weight loss. PACAP38 infused into the lateral ventricles did not alter weight, suggesting that the effects of BNST-infused PACAP were not mediated by leakage into the ventricular system. These data suggest that PACAP receptor activation in posterior BNST subregions can produce anorexia and weight loss, and corroborate growing data implicating central PACAP activation in mediating the consequences of stressor exposure.

Neuropsychopharmacology (2014) 39, 16|4-1623; doi: I0.1038/npp.20 I4.8; published online 12 February 20I4
\end{abstract}

Keywords: extended amygdala; pituitary adenylate cyclase-activating polypeptide; bed nucleus of the stria terminalis

\section{INTRODUCTION}

Recent gene association studies have implicated pituitary adenylate cyclase-activating peptide (PACAP) systems in several psychiatric disorders that may be associated with stressor exposure, including post-traumatic stress disorder (PTSD, Ressler et al, 2011), major depressive disorder (MDD; Hashimoto et al, 2010), and schizophrenia (Hashimoto et al, 2007). These studies corroborate evidence from rodent and primate models suggesting that the activation of PACAP systems is critical for functional stress response systems, and disrupted PACAP signaling may underlie the maladaptive consequences of stressor exposure (Dore et al, 2013; Hammack et al, 2009; Michopoulos et al, 2012; Stroth et al, 2011). The ubiquitous role for PACAP signaling in regulating activity at multiple levels of stress responding, including all three levels of the hypothalamicpituitary-adrenal (HPA) axis and extrahypothalamic sites associated with stress and anxiety, led Stroth and Eiden to

*Correspondence: Professor SE Hammack, Department of Psychology, University of Vermont, 2 Colchester Avenue, Dewey Hall, Burlington, Vermont 05405, USA, Tel: + I 802656 I04I, Fax: + I 8026568783 , E-mail: shammack@uvm.edu

Received 22 November 2013; revised 17 December 2013; accepted 9 January 2014; accepted article preview online 17 January 2014 describe PACAP as a 'master regulator' of stress responding (Stroth et al, 2011). Although increasing data suggest that PACAP signaling is a critical regulator of stress responding and may have a role in stress-related psychopathology, the function of PACAP in specific stress circuits remains to be described.

Substantial data has also implicated the bed nucleus of the stria terminalis (BNST) in stressor responding, and activation of different BNST subregions has been shown to mediate the inhibition or excitation of the hypothalamic paraventricular nucleus (PVN) by other extrahypothalamic brain regions, such as the ventral subiculum of the hippocampus and the medial prefrontal cortex (Radley et al, 2009; Radley and Sawchenko, 2011). BNST activity has also been argued to mediate anxiety-like behavior in rodents (Pego et al, 2008; Waddell et al, 2006; Walker et al, 2003), nonhuman primates (Kalin et al, 2005), and humans (Somerville et al, 2010; Straube et al, 2007). The BNST is particularly important in mediating sustained anxiety-like behavioral changes that result from exposure to long duration threats (Waddell et al, 2006), and also has a role in mediating stress-induced anorexia and associated reductions in weight gain (Choi et al, 2008a; Choi et al, 2007; Roman et al, 2012). Many of these consequences of stressor exposure are likely mediated by the activation of BNST corticotropin-releasing hormone (CRH) signaling 
(Ciccocioppo et al, 2003). Moreover, several studies have suggested that indices of BNST neuroplasticity are enhanced after chronic or repeated stress; BNST volume and dendritic length/branching, the expression of stress-related neuropeptides including PACAP, and indices of synaptic strength are all increased following repeated stress or chronic administration of drugs of abuse (Hammack et al, 2009; Krawczyk et al, 2011; Pego et al, 2008; Vyas et al, 2003).

The effects of PACAP on stress- and anxiety-like behavior may be mediated specifically via actions within the BNST. PACAP and PAC1 receptor mRNA expression is elevated in male rats within the dorsolateral BNST after a 7-day repeated variate stress paradigm, and intra-BNST PACAP infusion increases anxiety-like behavior (Hammack et al, 2009). Consequently, we have argued that increased BNST PACAP signaling may mediate many of the behavioral consequences of stressor exposure. As noted above, one consequence of stressor exposure includes the regulation of food intake, and PACAP systems may regulate food intake at multiple levels. PACAP and its receptors are expressed in central regions that regulate food intake and homeostasis (Hannibal et al, 1995; Masuo et al, 1993; Piggins et al, 1996; Shioda et al, 1997), and central PACAP administration reduces food intake and weight gain in many species, including rats, mice, chicks, and goldfish (Chance et al, 1995; Dore et al, 2013; Matsuda et al, 2005a; Mizuno et al, 1998; Morley et al, 1992; Tachibana et al, 2003b). Moreover, PACAP can inhibit food intake via activation of the hypothalamic melanocortin system (Mounien et al, 2009).

Because anorexia and/or reduction in weight gain is a common stress response that may be mediated by the activation of the BNST (Ciccocioppo et al, 2003; Roman et al, 2012), the present experiments were designed to determine whether BNST PACAP activation can alter food intake and weight gain in male and female rats in a manner similar to that observed following repeated stressor exposure. Because different subregions of the BNST may have different roles in the regulation of stress responding (Choi et al, 2007), we investigated the function of PACAP in different BNST subregions.

\section{MATERIALS AND METHODS}

\section{Subjects}

Adult male and ovariectomized (OVX) female SpragueDawley rats were obtained from Charles River Laboratories (Canada) weighing 250-300 g at the start of experimentation (male rats weighed $\sim 350 \mathrm{~h} 400 \mathrm{~g}$ and female rats $\sim 275 \mathrm{~h}$ $325 \mathrm{~g}$ on the day of infusion for all experiments). Rats were single-housed with a 12-h light/dark cycle, with lights on at 0700 hours and off at 1900 hours, and were allowed food and water access ad libitum. They remained in their home cages for 1 week prior to experimentation. All procedures were approved by the Institutional Animal care and Use Committee of the University of Vermont.

\section{Surgery}

Animals were anesthetized with $1.5-3.5 \%$ isoflurane in an induction chamber. After having their heads shaved, rats were placed in a stereotaxic apparatus (David Kopf
Instruments, Tujunga, CA), where their heads were secured in place with 'blunt' ear bars. Once the area was sterilized, an incision was made and four hemostats were used to keep the skull exposed. The skull was leveled and four burr holes were drilled in which jewelry screws were fixed to help secure the cannula. Guide cannulae (22 gauge, Plastics One, Roanoke, VA) were mounted onto each of the stereotaxic arms, which were set at a $20^{\circ}$ angle. Cannulae were lowered to bregma and were then moved posterior and lateral using coordinates that were obtained from the Paxinos and Watson rat brain atlas (5th edition, 2005; 6th edition, 2007). Cannulation coordinates varied for the different experiments, and will be given in detail below (infusions extended $1 \mathrm{~mm}$ beyond the tip of the cannulae for all experiments except experiment 4; intracerebroventricular (ICV) infusions were made at the tip of the cannulae). Once cannulae were lowered to the ventral coordinate, a dental cement skullcap was applied which, along with the screws, secured them in place. Wire stylets that extended $1 \mathrm{~mm}$ past the tip were inserted into the guide cannula, in order to prevent clogging. Before being removed from the stereotaxic apparatus, female rats were implanted with $17 \beta$ Estradiol or cholesterol vehicle slow-release capsules, subcutaneously, under the scruff of the neck. All animals were subcutaneously administered lactated ringers solution as well as an analgesic $(5 \mathrm{mg} / \mathrm{kg}$ Metacam, Boehringer Ingelheim Vetmedica, St Joseph, MO administered once immediately after surgery and once the following day). After the animals woke from surgery, they were returned to their home cages and were allowed to recover for 1 week, during which they were weighed and handled daily.

\section{Drugs}

PACAP (1-38), a PACAP agonist, was obtained from the American Peptide Company (Sunnyvale, CA) and was mixed into a vehicle solution consisting of $1 \%$ bovine serum albumin, (Santa Cruz Biotechnology, Santa Cruz, CA) in $9 \%$ saline, and used at either $0,0.1,0.5$, or $1.0 \mu \mathrm{g}$ in a volume of $0.5 \mu \mathrm{l}$ per side (such that the total amounts of PACAP infused were 0, 0.2, 1.0, $2.0 \mu \mathrm{g})$. For experiments 3 and 4, $1.0 \mu \mathrm{g}$ of PACAP was infused into each side (such that the total amount of PACAP infused was $2 \mu \mathrm{g}$ ) at a volume of $0.25 \mu \mathrm{l}$.

\section{Infusion Procedure}

For all experiments, animals were pseudo-randomly assigned into groups so that all groups started with a similar average weight. Infusions were made between 0915 hours and 1045 hours using a $10 \mu \mathrm{l}$ (experiments 1 and 2) or a $1 \mu \mathrm{l}$ (experiments 3 and 4) Hamilton syringe (Hamilton Company, Reno, NV). The syringe was attached via tubing to a 28 gauge internal cannula (Plastics One, Roanoke, VA) and was loaded with the vehicle solution or PACAP38. Rats were brought into the lab and were wrapped in a towel and lightly restrained. The stylet was removed from one side, the internal cannula was inserted into the guide cannula and then the specified volume of solution was infused (see specific experiment methods below). The internal cannula was left in for $60 \mathrm{~s}$, was slowly removed, and then the same procedure was performed on the other side. This procedure 
took $<5$ min per animal, and afterwards animals were returned to their homecage and the colony room.

\section{Weight Measurement}

Animal body weight and food and water weights were measured for 3 days. Measurement was taken between 0900 and 1030 hours, starting immediately prior to infusion, and then again 24 and $48 \mathrm{~h}$ later. We have typically administered our treatments during this time to maximize potential stress effects (Hammack et al, 2009), as this is a period when corticosterone levels are low in rodents. Because we have observed long-term changes in anxiety-like behavior following intra-BNST PACAP infusion (Hammack et al, 2009), we expected changes in food/water intake and weight to be similarly long-lasting.

\section{Histology}

Upon completion of each study, rats were anesthetized with Fatal-Plus Solution (Vortech, Dearborn, MI) and perfused transcardially with a saline $(0.9 \%)$ heparin $(0.1 \%$; Sagent, Schaumburg, IL) solution, followed by $4 \%$ paraformaldehyde. Brains were postfixed at $4{ }^{\circ} \mathrm{C}$ for at least $24 \mathrm{~h}$ in $4 \%$ paraformaldehyde. Fixed tissue was cut using a cryostat, and floating sections were collected at $60 \mu \mathrm{m}$ thickness. Mounted sections were then stained with a cresyl violet stain and coverslipped. Cannula placements were visualized using a $4 \times$ Nikon Objective on an Olympus microscope.

\section{Statistics}

Statistical analysis was completed using SPSS version 20 (IBM Software, Armonk, NY) and graphical representations were completed using GraphPad version 6 (GraphPad Software, San Diego, CA). Rats were eliminated from analysis for BNST cannulation experiments if cannulae placement fell outside the histological boundary of the BNST, or fell within the lateral ventricles. In addition, rats were eliminated if their weight gain/loss was more than two standard deviations away from the treatment mean. Twoway ANOVA was used to calculate overall group differences and interactions followed by Bonferroni post hoc test; some comparisons between groups were completed using $t$-tests.

\section{Experimental Procedure}

Experiment 1. All experiments were conducted with a between-subjects design. The aim of experiment 1 was to determine if intra-BNST PACAP38 infusions altered body weight and food and water intake in male $(n=32)$. Bilateral BNST cannulations were performed as described above using coordinates that targeted the BNST, AP $-0.26 \mathrm{~mm}$, $\mathrm{ML}+3.8 \mathrm{~mm}$, DV $-5.3 \mathrm{~mm}$. One week after surgery, rats were infused with $0.0,0.1,0.5$, or $1.0 \mu \mathrm{g}$ PACAP38 in a volume of $0.5 \mu \mathrm{l}$ per side as described above. Food, water, and rat body weights were assessed immediately prior to infusion, and for 2 days following between 0900 and 1030 hours.

Experiment 2. We have previously reported that alterations in PACAP systems are associated with symptoms of

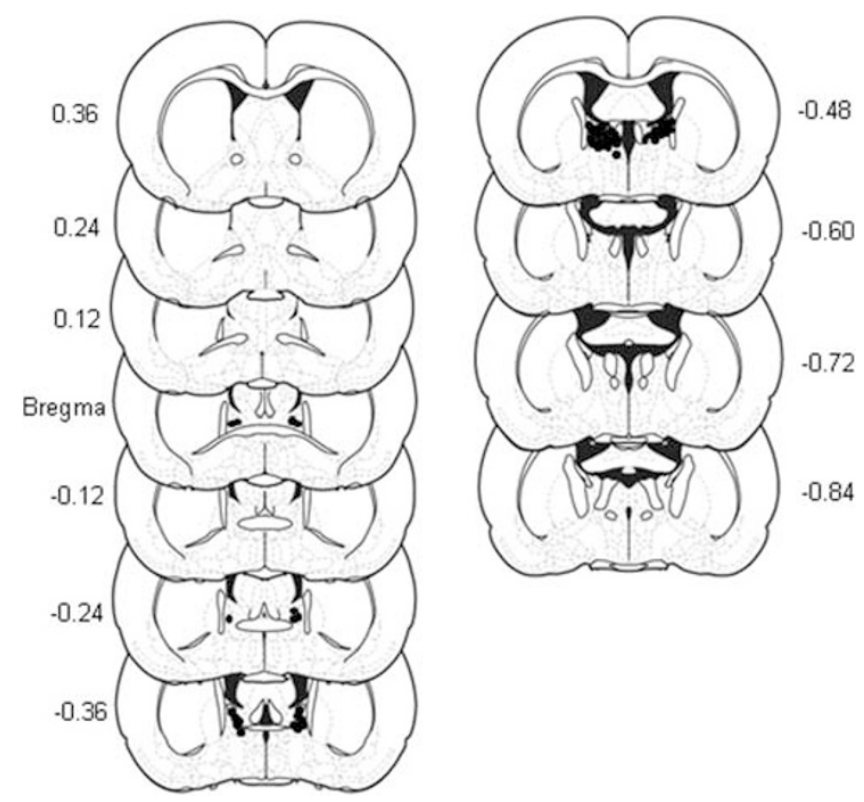

Figure I Cannula placements for experiment I, male rats. Coronal sections are measured in millimeters from bregma, black dots represent site of infusion within the BNST.

PTSD in women, but not in men, and E2 treatment upregulated BNST PACAP transcript in female rats (Ressler et al, 2011). The aim of experiment 2 was to determine if intra-BNST PACAP38 infusions altered body weight and food and water intake in female rats, and whether this treatment interacted with E2 in OVX female rats with or without E2 replacement $(n=52)$ with or without E2 replacement. Bilateral BNST cannulations were performed as described in experiment 1; OVX female rats were either implanted with an E2 or cholesterol (vehicle) slow release capsule. One week after surgery, rats were infused with $0.0,0.5$, or $1.0 \mu \mathrm{g}$ PACAP38 in a volume of $0.5 \mu \mathrm{l}$ per side as described above. Food, water, and rat body weights were assessed immediately prior to infusion, and for 2 days following between 0900 and 1030 hours. At the time of euthanasia, trunk blood was collected from female rats for the measurement of E2, using an Estradiol Enzyme Immunoassay Kit (Cayman Chemical, Ann Arbor, MI).

Experiment 3. The histology from experiment 1 showed that, although aiming for the BNSTov, most placements ended up in the posterior portion, specifically the principal nucleus (BNSTpr, see Figure 1). Hence, experiment 3 was designed to determine if the effects of PACAP38 on weight differed when injected into the anterior and posterior BNST. Bilateral BNST cannulations were performed as described above in male rats $(n=51)$. For anterior placements, coordinates were the same as those used in experiment 1 ; $\mathrm{AP}-0.26 \mathrm{~mm}, \mathrm{ML}+3.8 \mathrm{~mm}, \mathrm{DV}-5.3 \mathrm{~mm}$; however, we adjusted our bregma assessment to more accurately target the BNSTov. For posterior placements, coordinates were aimed at the BNSTpr, AP $-0.8 \mathrm{~mm}, \mathrm{ML}+3.8 \mathrm{~mm}$, DV $-6.6 \mathrm{~mm}$. One week after cannulation, $1.0 \mu \mathrm{g}$ PACAP38 or equivolume vehicle was infused into the BNST. We lowered the infusion volume to $0.25 \mu \mathrm{l}$ per side to reduce spread to other BNST subregions. 
Experiment 4. Several studies have suggested that ICV PACAP infusion produces anorexia and weight loss in a variety of species (Chance et al, 1995; Matsuda et al, 2005b; Mizuno et al, 1998; Morley et al, 1992). Because the BNST borders on the ventral aspect of the lateral ventricles, it was possible that the effects of BNST PACAP observed in the previous experiments were mediated via an action outside the BNST due to leakage of PACAP38 into the ventricle system. However, it is notable that typically ICV PACAP studies have used larger doses and/or much larger infusion volumes than those implemented in experiments 1 and 2 . Experiment 3 was designed to determine whether PACAP38 infused into the lateral ventricles could actually produce evidence of weight loss using the same procedures implemented in experiments 1 and 2. ICV cannulation surgeries were performed using the surgical methods described above with the cannulae in the dorsal aspect of the lateral ventricles (respect to bregma: $\mathrm{AP}-0.3, \mathrm{ML}$ +3.0 , DV -3.4$)$, again in male rats $(n=19)$. Placements for ICV surgeries were verified during surgery by observing the movement of a small amount of sterile isotonic saline in a length of tubing attached to the cannulae. Following 1 week of post-operative care, rats were pseudorandomly matched by weight into vehicle treatment or $1.0 \mu \mathrm{g} / 0.25 \mu \mathrm{l}$ PACAP38, the same PACAP38 dose and infusion procedures that we found to effectively reduce weight in experiment 3. Infusions and weight assessment were conducted in a similar manner as described above.

\section{RESULTS}

\section{Experiment 1}

The centers of infusion for PACAP-infused rats accepted for analysis are shown in Figure 1. Note that for all histology figures, some of the dots demarcating infusion centers may represent infusion sites for multiple rats, if overlap between two sites was complete. For male rats, although the infusion sites were aimed at the BNSTov, many infusions ended up in posterior BNST regions, particularly around the region of the BNSTpr, although it is likely that the infusion volume spread throughout the anterior/posterior extent of the BNST. For experiment 1, we accepted data from rats with cannula placements in any BNST subregion for analysis.

In the $24 \mathrm{~h}$ following BNST PACAP infusion, a one-way ANOVA revealed a significant effect of PACAP38 dose on weight, $\mathrm{F}(3,30)=4.91, p<0.01$, see Figure $2 \mathrm{a}$. Bonferroni post hoc test revealed a significant difference between the $0.0 \mu \mathrm{g}$ and the $1.0 \mu \mathrm{g}$ PACAP38 groups $(p<0.05)$. A one-way ANOVA also revealed an effect of PACAP38 dose on food intake, $\mathrm{F}(3,30)=3.18, p<0.05$ (Figure $2 \mathrm{~b}$ ), as well as on water intake, $\mathrm{F}(3,30)=3.72, p<0.05$ (data not shown). These results indicate that in male, BNST PACAP38 infusion produced weight loss in the $24 \mathrm{~h}$ period following infusion, and this effect was dose-dependent. Notably, this effect was transient, as body weight change did not differ between groups in the period $24-48 \mathrm{~h}$ following infusion; hence, both groups gained the same amount of weight during this time period (data not shown). Notably, there was no 'rebound' increase in weight in PACAP-infused rats during the period 24-48 $\mathrm{h}$ following infusion to compensate for the lost weight immediately after infusion.
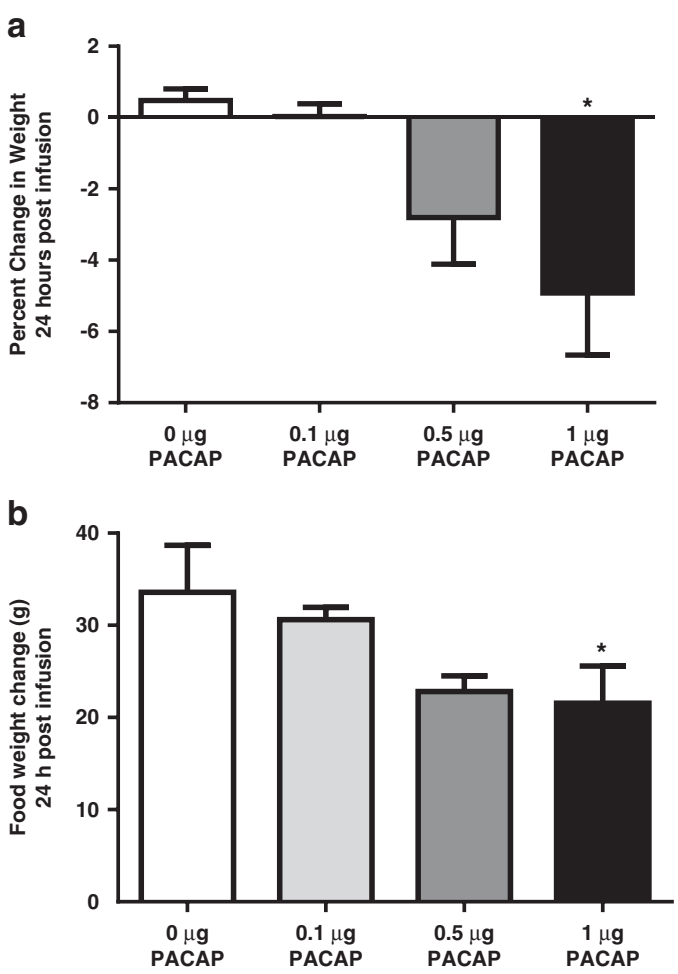

Figure 2 BNST PACAP reduces weight and food intake in male rats. (a) Dose-response percent weight change $24 \mathrm{~h}$ following PACAP infusion in male rats. (b) Left, dose-response food weight change $24 \mathrm{~h}$ following PACAP infusion in male rats. There was a main effect of PACAP for both measures. $* p<0.05$ compared with vehicle.

\section{Experiment 2}

The centers of infusion for PACAP-infused female rats accepted for analysis are shown in Figure 3. For female rats, infusions ended up throughout the anterior-posterior extent of the BNST, although many were concentrated in middle regions; it is likely that the infusion volume spread throughout the anterior/posterior extent of the BNST. Again, we accepted data from rats with cannula placements in any BNST subregion for analysis.

In female rats, implantation of E2 capsules produced E levels in reliably increased E2 levels in OVX rats an average of $26.17 \mathrm{pg} / \mathrm{ml}, t(46)=3.58, p<0.005$, to high physiological levels (proestrous levels; (Becker et al, 2005)). A two-way ANOVA revealed a significant main effect of PACAP, $\mathrm{F}(2,47)=3.638$, $p<0.05$, but no effect of E2 treatment, $\mathrm{F}(1,47)=0.0015$, $p>0.05$, and no interaction, $\mathrm{F}(2,47)=0.9325, \quad p>0.05$ (Figure 4a). Two-way ANOVA revealed a significant main effect of PACAP on food intake, $\mathrm{F}(2,47)=5.058, p<0.05$, but no effect of E2 treatment, $\mathrm{F}(1,47)=0.0006, p>0.05$, and no interaction, $F(2,47)=1.110, p>0.05$ (figure $4 \mathrm{~b}$ ). Notably, in female rats, intra-BNST PACAP did not alter water intake, $\mathrm{F}(2,43)=0.026, p>0.05$ (data not shown), nor was there an effect of E2 treatment on water intake, $\mathrm{F}(1,43)=1.201, p>0.05$ or an interaction between BNST PACAP and E2, $\mathrm{F}(2,43)=0.026, p>0.05$. Hence, like male rats, BNST PACAP38 infusion produced weight loss in the $24 \mathrm{~h}$ period following infusion in female rats, and this effect was dosedependent. Food intake was also reduced by BNST PACAP38 infusion in female rats, although water intake was not reduced in female rats. 


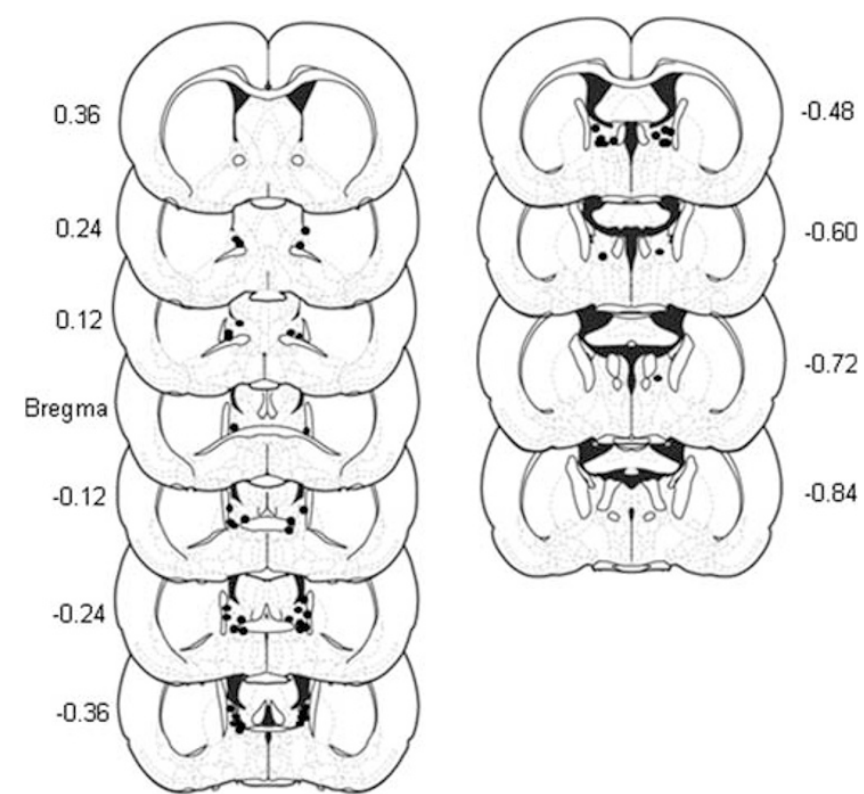

Figure 3 Cannula placements for experiment 2, female rats. Coronal sections are measured in millimeters from bregma, black dots represent site of infusion within the BNST.
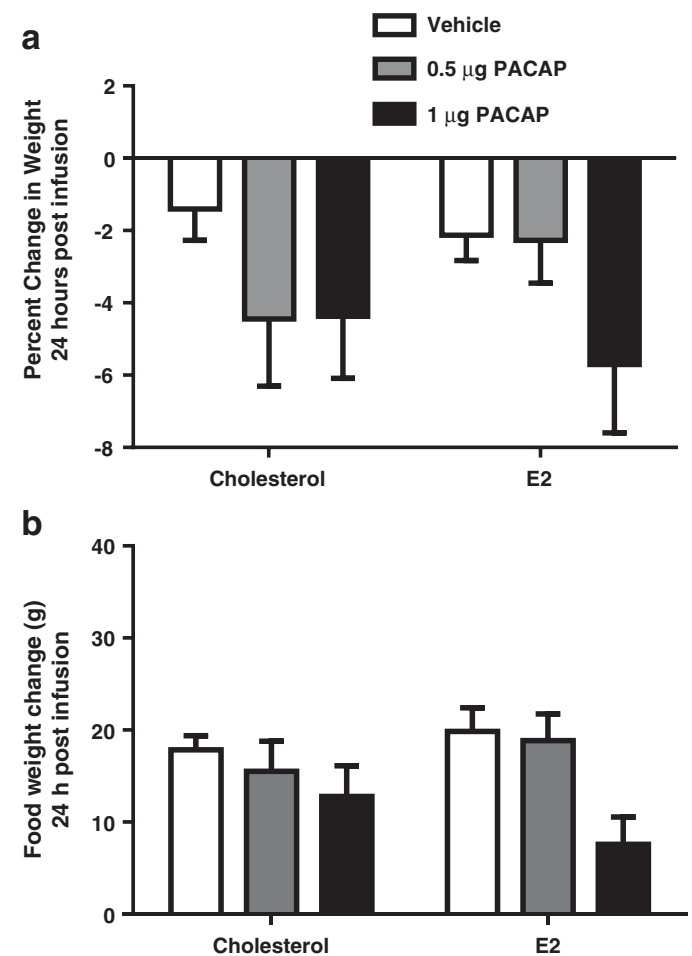

Figure 4 BNST PACAP reduces weight and food intake in female rats. (a) Dose-response percent weight change $24 \mathrm{~h}$ following PACAP infusion in female OVX rats, vehicle (left) and E2 replaced (right). (b) Doseresponse food weight change $24 \mathrm{~h}$ following PACAP infusion in female OVX rats, vehicle (left) and E2 replaced (right). There was a main effect of PACAP for both measures.

\section{Experiment 3}

As noted above, in experiments 1 and 2 we examined the potential difference in the role of BNST PACAP in regulating weight change and food/water intake in male

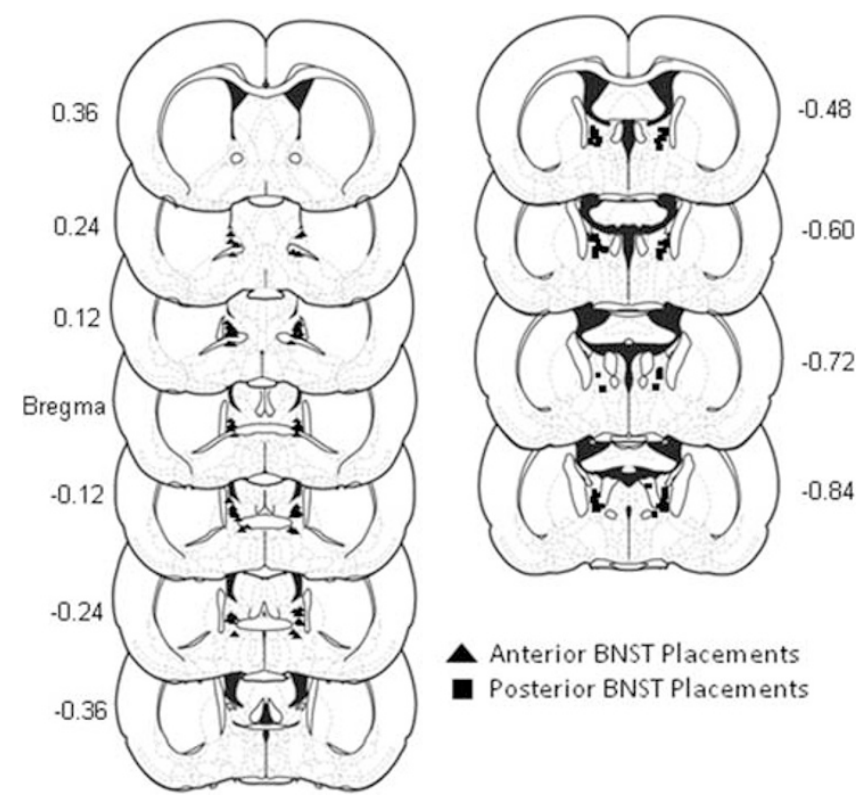

Figure 5 Cannula placements for experiment 3. Coronal sections are measured in millimeters from bregma. Black triangles represent anterior BNST infusion sites. Black squares represent posterior BNST infusion sites.

and female rats. Hence, PACAP38 was infused into either the anterior portion or posterior BNST prior to the assessment of weight and food/water intake in male rats. The centers of infusion for PACAP-infused rats accepted for analysis are shown in Figure 5, and placements that were confined to either the anterior or posterior portions of the BNST, according to the Paxinos and Watson rat brain atlas (6th edition, 2007), were included in analyses. One animal was excluded from analysis due to missed placement outside of the BNST and another was excluded because one cannula was located in the anterior portion and the other was in the posterior portion.

Analyses were conducted on the change in weight induced by $1.0 \mu \mathrm{g} / 0.25 \mu \mathrm{l}$ BNST PACAP38 infusion, which was determined by the difference between body weight measured just prior to infusion and that measured $24 \mathrm{~h}$ after infusion. A two-way ANOVA examining the effects of BNST placement (anterior or posterior) and PACAP38 treatment (1.0 $\mu \mathrm{g}$ PACAP38 or vehicle) on body weight change $24 \mathrm{~h}$ post-infusion revealed that the effects of BNST PACAP38 infusion depended on placement (Figure 6a), as there was a significant BNST placement/PACAP38 interaction, $\mathrm{F}(1,48)=4.60, p<0.05$. Although there was no significant main effect of BNST placement, $\mathrm{F}(1,48)=1.05, p>0.05$, there was a significant main effect of PACAP38 treatment, $\mathrm{F}(1,48)=4.83, p<0.05$. $T$-tests conducted separately for anterior and posterior BNST placements revealed no significant effect of PACAP38 infusion in the anterior BNST, $t(21)=0.2691, p>0.05$, but did reveal a significant effect of PACAP38 infusion into the posterior BNST, $t(28)=2.656, p<0.05$.

As in experiments 1 and 2, we measured the amount of food and water ingested during the $24 \mathrm{~h}$ post-infusion time period. A two-way ANOVA examining BNST placement and PACAP38 treatment on food intake found no main effect of 


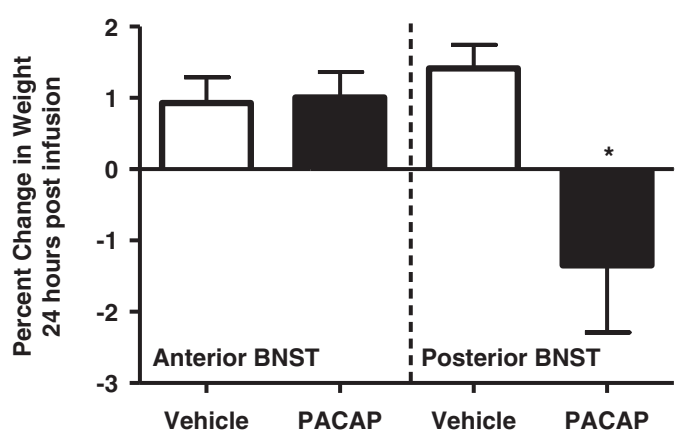

b

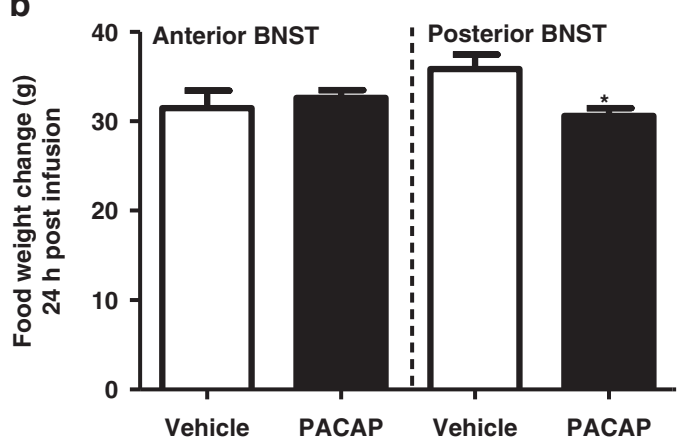

Figure $\mathbf{6}$ The effects of PACAP on food intake and weight are mediated by the posterior BNST. (a) Percent weight change $24 \mathrm{~h}$ following PACAP infusion into the anterior (left) and posterior (right) BNST. (b) Food weight change $24 \mathrm{~h}$ following PACAP infusion into the anterior (left) and posterior (right) BNST. $* p<0.05$ compared with posterior vehicle.

either BNST placement, $\mathrm{F}(1,48)=0.10, p>0.05$, (Figure $6 \mathrm{~b}$ ), or of PACAP38, $\mathrm{F}(1,48)=0.08, p>0.05$, but again there was a significant interaction between BNST placement and PACAP38 infusion, $\mathrm{F}(1,48)=6.26, p<0.05$. Again, there was no difference between PACAP38 and vehicle-treated animals on food intake when infusions were made into the anterior BNST, $t(21)=0.9455, p>0.05$. PACAP38 infusion into the posterior BNST, however, significantly reduced food intake, $t(28)=2.964, p<0.05$ (Figure $6 \mathrm{~b}$ ). No group differences were found for water intake (data not shown).

\section{Experiment 4}

In experiment 4, we examined whether ICV PACAP38 infusion could produce the same effects found following infusion into the BNST. There was no effect of bilateral PACAP38 infusion into the lateral ventricles on weight, $(t(17)=1.416, p=0.1750$, (Figure $7 \mathrm{a})$ or food intake, $t(17)=0.1222, p=0.9042$, (Figure $7 \mathrm{~b}$ ) in the $24 \mathrm{~h}$ postinfusion. In order to determine whether we were sufficiently statistically powered to observe an effect of PACAP, we ran a power analysis using $G^{*}$ POWER 3.1.2. Using the means and standard deviations we obtained for the effect of $1.0 \mu \mathrm{g}$ PACAP38 infused into the BNST on weight loss, we calculated an effect size of 1.881. Conducting a power analysis for a two-tailed $t$-test with this effect size and an alpha level of 0.05 suggested that we should observe an effect of PACAP with nine rats per group, which is consistent with the number of animals used (9 vehicleand 10 PACAP-treated rats).

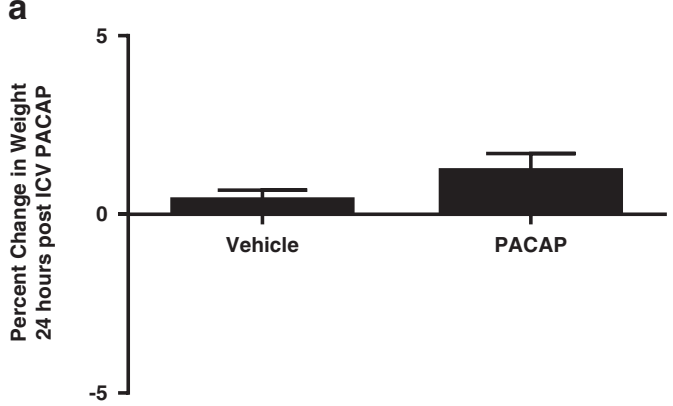

b

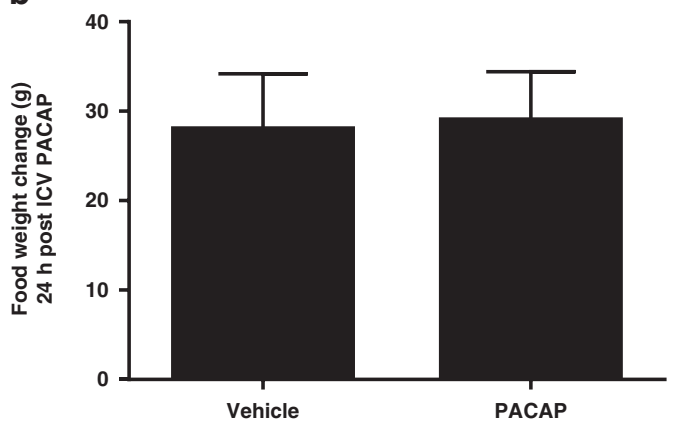

Figure 7 The effects of BNST PACAP were not mediated by leakage into the ventricular system. (a) Percent weight change $24 \mathrm{~h}$ following ICV PACAP infusion. (b) Food intake $24 \mathrm{~h}$ following ICV PACAP infusion.

\section{DISCUSSION}

PACAP38 infusion into the BNST produced anorexia and substantial weight loss in the $24 \mathrm{~h}$ following infusion in both male and female rats. These results are consistent with reports suggesting that central PACAP systems are involved in the regulation of food intake (Chance et al, 1995; Dore et al, 2013; Matsuda et al, 2005a; Mizuno et al, 1998; Morley et al, 1992; Mounien et al, 2009; Tachibana et al, 2003b). Although substantial data have suggested that PACAP action within the hypothalamus may be critical for the regulation of feeding behavior (for example, PACAP actions of food intake are mediated by activation of the hypothalamic melanocortin system (Mounien et al, 2009)), our results suggest that the BNST may also be a critical site of action for regulation of food intake by PACAP.

Given the role of the BNST in the regulation of stress responding, these results are consistent with our previous reports suggesting an involvement of BNST PACAP in the behavioral consequences of stressor exposure (Hammack et al, 2009; Hammack et al, 2010). Moreover, in experiment 3, we found that PACAP action in the posterior BNST, in particular the BNSTpr, likely mediates these effects. These results augment our previous finding that PACAP mRNA is elevated in the BNST following chronic stress and that intraBNST PACAP infusion produces many of the behavioral consequences of stressor exposure (Hammack et al, 2009), and also support mounting evidence suggesting a role for PACAP (eg, Stroth et al, 2011) and BNST activation (eg, Herman et al, 2005; Radley et al, 2009; Radley and Sawchenko, 2011) in mediating responses to stressful stimuli.

It is unlikely that the effects of BNST PACAP infusion were mediated by leakage of PACAP into the ventricular system leading to activity at a site other than the BNST. 
In order to minimize leakage, cannulae were aimed at the BNST at an angle to avoid the lateral ventricles. Moreover, we found that the infusion into the lateral ventricles did not reduce food intake or weight. Although ICV PACAP has been previously shown to lower weight (Matsuda et al, 2005b; Mizuno et al, 1998; Morley et al, 1992; Tachibana et al, 2003a), it is notable that those studies infused much larger PACAP doses and utilized larger infusion volumes to promote spread, as compared with the procedures used in the current report.

Stressor exposure has been shown to produce an anorectic effect in several rodent species, particularly following a chronic restraint or immobilization stress (Krahn et al, 1990; Marti and Armario, 1997; Marti et al, 1994), and BNST activity may have an important role in stress-induced anorexia. For example, the infusion of $\mathrm{CRH}$ into the BNST, but not the central amygdala or locus ceruleus, was able to produce anorexia, and intra-BNST infusion of nociceptin/orphanin $\mathrm{FQ}$, an opioid peptide known to oppose the effects of $\mathrm{CRH}$, attenuated this CRHinduced anorexia (Ciccocioppo et al, 2003). Furthermore, we have previously shown that excitotoxic lesions of the BNST oval nucleus (BNSTov) blocked the attenuated weight gain normally observed following repeated stressor exposure (Roman et al, 2012), although it is notable that in some studies lesions to the anterior or posterior BNST did not alter the effects of chronic stress on weight, although these studies did not target the BNSTov (Choi et al, 2008a; Choi et al, 2007; Choi et al, 2008b). Although several studies have implicated BNST activity in stress-induced anorexia, Jennings et al. (2013) identified a GABAergic projection from the BNST to the lateral hypothalamus (LH) that when activated produced a large increase in food consumption (Jennings et al, 2013). Together, these studies suggest that the BNST is a key regulator of feeding behavior; whether BNST activation inhibits or excites feeding may depend on the distinct BNST circuits activated, as well as pattern of activity within particular BNST outputs.

In addition to projecting to the $\mathrm{LH}$, as mentioned above, the BNST also sends projections to other brain areas known to be involved in feeding, such as the hypothalamic arcuate nucleus (ARC; Dong et al, 2001; Dong and Swanson, 2004). Neurons in the ARC express many peptides that are known to regulate feeding, including anorexigenic peptides such as proopiomelanocortin and cocaine- and amphetamine-regulated transcript, and orexigenic peptides, such as neuropeptide Y (NPY) and agouti-related peptide (AGRP) (Valassi et al, 2008). It is possible that PACAP38 infusion into the BNST may activate ARC afferents that regulate ARC activity, and thus lead to weight loss. In addition, it has been found that BNST neurons express several different feedingrelated peptides, including NPY (Chronwall et al, 1985), melanocortin-4 (Gelez et al, 2010), AGRP (Haskell-Luevano et al, 1999), and CRH (Lim et al, 2006; Richard et al, 2004), and BNST PACAP infusion could regulate the release of these other peptides in other feeding-related brain regions like the ARC.

The anorexia we observed following BNSTpr PACAP38 infusion may also have been a consequence of the activation of other stress response systems. For example, attenuated weight gain can be a consequence of repeated treatment of hormones that are released during HPA axis activation, including corticosterone (Coburn-Litvak et al, 2003) and adrenocorticotropic hormone (Turner et al, 1998). Notably, the BNST is heavily implicated in the regulation of HPA axis activity during stressor exposure, and this role has been shown to differ between different BNST subregions. For example, Choi et al. found that the activation of anterior and posterior BNST regions excites and inhibits HPA activity, respectively (Choi et al, 2007; Choi et al, 2008b). On the other hand, Bingham et al. (2011) found that posterior BNST androgen receptor activation led to excitation of the PVN of the hypothalamus in male rats subjected to restraint stress. These data suggest that activation of the anterior and posterior BNST can lead to or inhibit a stress response, although the conditions that lead to excitation or inhibition may be complex (see below). Hence, different BNST subregions have different roles in the regulation of HPA axis activity following stressor exposure, and it is reasonable to predict that other stress responses, such as stressinduced anorexia, may also be regulated differently by different BNST subregions.

It remains possible that the effects of BNST PACAP on feeding behavior may have been mediated indirectly, by regulating other processes that could alter feeding. For example, PACAP systems have a role in the control of circadian rhythms, regulating activity in the suprachiasmatic nuclei (see Harmar (2003) and Mertens et al (2007) for review). Although our results suggest that the site of action in the present studies was the BNST, it is notable that the BNST oval nucleus, a region with high PACAP expression (Hammack et al, 2009; Kozicz et al, 1997, 1998), also expresses PERIOD2 protein levels in a circadian fashion (Amir et al, 2004).

Here we found that in male rats, the BNSTpr was the likely site of action for the anorexic effects of BNST PACAP infusion, and PACAP infusion into the anterior BNST did not alter food intake or weight gain. Although BNST PACAP-induced anorexia is consistent with other data suggesting that BNST PACAP can mimic other stressrelated responses (ie, anxiety-like behavior, Hammack et al, 2009), it is unknown whether the different behavioral effects of BNST PACAP infusion are mediated by the same neurocircuitry. For example, the anxiogenic effects of BNST PACAP may be more dependent on anterior BNST activation, where PACAP fibers have been shown in close proximity to CRH-expressing neurons (Kozicz et al, 1997), and PACAP has been shown to enhance excitatory transmission in a similar $\mathrm{CRH}$-rich region related to emotional behavior, the central amygdala (Cho et al, 2012). Notably, Dore et al. (2013) found that the anorexic effect of ICV PACAP was not attenuated by CRH antagonism (Dore et al, 2013); hence, it is unlikely that BNST PACAP is upstream of CRH in PACAP-induced anorexia.

However, the role for different BNST subregions in these different stress responses may be altered in stressed rats. For example, Choi et al (2008a,b) found that although anteroventral BNST lesions reduce the HPA-axis response to an acute stressor, the response to an acute stressor was increased following these same lesions in chronically stressed rats. Carvalho-Netto et al (2011) found that chronically stressed female rats exhibited reduced synaptic density in the BNSTpr; if BNSTpr activation is an important inhibitor of HPA-activity, then reduced BNSTpr neuroplasticity may 
be indicative of compromised negative feedback to the HPA axis (Carvalho-Netto et al, 2011). In addition, we have reported an upregulation of $\mathrm{PACl}$ receptor transcript in the BNST in chronically stressed rats, although the subregional distribution of this upregulation is unknown. Hence, although the BNSTpr seems to be site of action for the anorectic effects of BNST PACAP infusion in naïve rats, these data do not preclude a role for other BNST subregions in anorexia. Interestingly, Resch et al. (2013) reported that PACAP infused into the hypothalamic PVN or ventromedial nuclei reduced food intake and some PVN PACAP afferents may originate in the medial part of the anterior BNST (Resch et al, 2013), suggesting that PACAP may be conserved across several nuclei that regulate feeding behavior, and that the activation of PACAP neurons in the anterior BNST may regulate food intake in some contexts.

On the basis of the current study, it is unknown whether the site of action for the anorexic effects of BNST PACAP in female rats was the anterior and/or posterior BNST. The placements in experiment 2 extended throughout the BNST, although many clustered in the middle of the anteriorposterior axis, and with the large infusion volume in experiment 2 , it is likely that PACAP reached the entire extent of the BNST. However, it is notable that the BNST (and in particular the BNSTpr) is also one of the most sexually dimorphic areas in the brain and sex differences in BNST function may have an important role in the sex differences observed in the diagnoses of several stressrelated clinical disorders. For example, women are more likely than men to develop many anxiety or mood disorders over the course of their lifetimes (Kessler et al, 2005), including panic disorder, generalized anxiety disorder, social anxiety disorder, PTSD, agoraphobia, and other specific phobias, MDD, and eating disorders (McLean et al, 2011). In rats, sex steroid hormone receptors, such as estrogen and androgen receptors, are highly expressed in the posterior BNST (Shughrue et al, 1997; Simerly, 1993) and posterior BNST cell number and volume are higher in male rats than in female rats (Del Abril et al, 1987; Hines et al, 1992).

We have previously shown that circulating levels of PACAP and a single-nucleotide polymorphism (SNP) in the $\mathrm{PAC1}$ receptor gene are associated with symptoms of PTSD in women, but not men, although methylation of the PAC1 receptor gene was associated with PTSD in both sexes (Ressler et al, 2011). Moreover, the PAC1 receptor gene SNP was in the region of a putative estrogen response element, and E2 treatment upregulated BNST PACAP transcript in female rats. Together, these results suggest that PACAP interactions with E2 may play a role in the sex differences observed in several stress-related psychopathologies.

In the present report, we did not observe a significant interaction between estrogen and PACAP treatment. It is possible that there was a subtle interaction that might have been revealed with more power, or a different E2 treatment regimen. For example, our E2 replacement strategy led to sustained levels of E2 in female rats that did not mimic the natural fluctuation of E2 throughout the estrous cycle; it is possible that interactions between E2 and PACAP could depend on cycling hormone levels. Moreover, although we observed a significant effect of our E2 treatment, circulating E2 was observed in OVX rats, which may be associated with release from other organs (ie, the adrenal cortex, Strom et al, 2008) or obtained through diet.

It is tempting to compare the effects of BNST PACAP on weight and food intake between male and female rats in the present report; however, several aspects of the present study likely confound sex comparisons. For example, female rats were gonadectomized, whereas male rats were not, preventing a true comparison of sex differences in these measures. Also, a blood sample was obtained in female rats $30 \mathrm{~min}$ after BNST PACAP infusion; this procedure may represent a small stressor that could alter food intake and weight, and blood was not sampled in male rats. Hence, this report is meant to be an initial investigation assessing the effects of BNST PACAP in male and female rats, without attempting to make statistical comparisons of sex differences in the magnitude of these effects.

\section{Conclusions}

Here we showed that PACAP38 infused into the posterior BNST, but not anterior BNST or ICV, mimics the weight loss and anorectic consequences of repeated stressor exposure. We found that this effect was apparent in both male and female rats; in female rats, the effects of PACAP did not seem to interact with E2 treatment, although there may be evidence for a subtle effect of E2. These data support a growing literature implicating PACAP and BNST activity in the regulation of food intake, and stress responding, which may lead to a better understanding of stress-related psychopathology in humans.

\section{FUNDING AND DISCLOSURE}

The work by Dr Toufexis and Dr Braas has been funded by the National Institutes of Health. Dr Hammack's work has been funded by the National Institutes of Health, the National Alliance for Research on Schizophrenia and Depression (NARSAD) and the University of Vermont College of Arts and Sciences. This work was supported by grants MH-97988 and MH-072088 (SEH), as well as funds from the Center of Biomedical Research Excellence (COBRE) in Neuroscience at the University of Vermont (National Institute of Health NCRR P20RR16435). The authors declare no conflict of interest.

\section{REFERENCES}

Amir S, Lamont EW, Robinson B, Stewart J (2004). A circadian rhythm in the expression of PERIOD2 protein reveals a novel SCN-controlled oscillator in the oval nucleus of the bed nucleus of the stria terminalis. J Neurosci 24: 781-790.

Becker JB, Arnold AP, Berkley KJ, Blaustein JD, Eckel LA, Hampson E et al (2005). Strategies and methods for research on sex differences in brain and behavior. Endocrinology 146: 1650-1673.

Bingham B, Myung C, Innala L, Gray M, Anonuevo A, Viau V (2011). Androgen receptors in the posterior bed nucleus of the stria terminalis increase neuropeptide expression and the stress-induced activation of the paraventricular nucleus of the hypothalamus. Neuropsychopharmacology 36: 1433-1443.

Carvalho-Netto EF, Myers B, Jones K, Solomon MB, Herman JP (2011). Sex differences in synaptic plasticity in stress-responsive 
brain regions following chronic variable stress. Physiol Behav 104: 242-247.

Chance WT, Thompson H, Thomas I, Fischer JE (1995). Anorectic and neurochemical effects of pituitary adenylate-cyclase activating polypeptide in rats. Peptides 16: 1511-1516.

Cho JH, Zushida K, Shumyatsky GP, Carlezon WA Jr., Meloni EG, Bolshakov VY (2012). Pituitary adenylate cyclase-activating polypeptide induces postsynaptically expressed potentiation in the intra-amygdala circuit. J Neurosci 32: 14165-14177.

Choi DC, Evanson NK, Furay AR, Ulrich-Lai YM, Ostrander MM, Herman JP (2008a). The anteroventral bed nucleus of the stria terminalis differentially regulates hypothalamic-pituitary-adrenocortical axis responses to acute and chronic stress. Endocrinology 149: 818-826.

Choi DC, Furay AR, Evanson NK, Ostrander MM, Ulrich-Lai YM, Herman JP (2007). Bed nucleus of the stria terminalis subregions differentially regulate hypothalamic-pituitary-adrenal axis activity: implications for the integration of limbic inputs. J Neurosci 27: 2025-2034.

Choi DC, Furay AR, Evanson NK, Ulrich-Lai YM, Nguyen MM, Ostrander MM et al (2008b). The role of the posterior medial bed nucleus of the stria terminalis in modulating hypothalamicpituitary-adrenocortical axis responsiveness to acute and chronic stress. Psychoneuroendocrinology 33: 659-669.

Chronwall BM, DiMaggio DA, Massari VJ, Pickel VM, Ruggiero DA, O'Donohue TL (1985). The anatomy of neuropeptide-Ycontaining neurons in rat brain. Neuroscience 15: 1159-1181.

Ciccocioppo R, Fedeli A, Economidou D, Policani F, Weiss F, Massi M (2003). The bed nucleus is a neuroanatomical substrate for the anorectic effect of corticotropin-releasing factor and for its reversal by nociceptin/orphanin FQ. J Neurosci 23: 9445-9451.

Coburn-Litvak PS, Pothakos K, Tata DA, McCloskey DP, Anderson BJ (2003). Chronic administration of corticosterone impairs spatial reference memory before spatial working memory in rats. Neurobiol Learn Mem 80: 11-23.

Del Abril A, Segovia S, Guillamon A (1987). The bed nucleus of the stria terminalis in the rat: regional sex differences controlled by gonadal steroids early after birth. Brain Res 429: 295-300.

Dong HW, Petrovich GD, Watts AG, Swanson LW (2001). Basic organization of projections from the oval and fusiform nuclei of the bed nuclei of the stria terminalis in adult rat brain. J Comp Neurol 436: 430-455.

Dong HW, Swanson LW (2004). Projections from bed nuclei of the stria terminalis, posterior division: implications for cerebral hemisphere regulation of defensive and reproductive behaviors. J Comp Neurol 471: 396-433.

Dore R, Iemolo A, Smith KL, Wang X, Cottone P, Sabino V (2013). CRF mediates the anxiogenic and anti-rewarding, but not the anorectic effects of PACAP. Neuropsychopharmacology 38: 2160-2169.

Gelez H, Poirier S, Facchinetti P, Allers KA, Wayman C, Bernabe J et al (2010). Neuroanatomical distribution of the melanocortin-4 receptors in male and female rodent brain. J Chem Neuroanat 40: 310-324.

Hammack SE, Cheung J, Rhodes KM, Schutz KC, Falls WA, Braas $\mathrm{KM}$ et al (2009). Chronic stress increases pituitary adenylate cyclase-activating peptide (PACAP) and brain-derived neurotrophic factor (BDNF) mRNA expression in the bed nucleus of the stria terminalis (BNST): Roles for PACAP in anxiety-like behavior. Psychoneuroendocrinology 34: 833-843.

Hammack SE, Roman CW, Lezak KR, Kocho-Shellenberg M, Grimmig B, Falls WA et al (2010). Roles for pituitary adenylate cyclase-activating peptide (PACAP) expression and signaling in the bed nucleus of the stria terminalis (BNST) in mediating the behavioral consequences of chronic stress. J Mol Neurosci 42: 327-340.

Hannibal J, Mikkelsen JD, Clausen H, Holst JJ, Wulff BS, Fahrenkrug J (1995). Gene expression of pituitary adenylate cyclase activating polypeptide (PACAP) in the rat hypothalamus Regul Pept 55: 133-148.

Harmar AJ (2003). An essential role for peptidergic signalling in the control of circadian rhythms in the suprachiasmatic nuclei. J Neuroendocrinol 15: 335-338.

Hashimoto R, Hashimoto H, Shintani N, Chiba S, Hattori S, Okada $\mathrm{T}$ et al (2007). Pituitary adenylate cyclase-activating polypeptide is associated with schizophrenia. Mol Psychiatry 12: 1026-1032.

Hashimoto R, Hashimoto H, Shintani N, Ohi K, Hori H, Saitoh O et al (2010). Possible association between the pituitary adenylate cyclase-activating polypeptide (PACAP) gene and major depressive disorder. Neurosci Lett 468: 300-302.

Haskell-Luevano C, Chen P, Li C, Chang K, Smith MS, Cameron JL et al (1999). Characterization of the neuroanatomical distribution of agouti-related protein immunoreactivity in the rhesus monkey and the rat. Endocrinology 140: 1408-1415.

Herman JP, Ostrander MM, Mueller NK, Figueiredo H (2005). Limbic system mechanisms of stress regulation: hypothalamopituitary-adrenocortical axis. Prog Neuropsychopharmacol Biol Psychiatry 29: 1201-1213.

Hines M, Allen LS, Gorski RA (1992). Sex differences in subregions of the medial nucleus of the amygdala and the bed nucleus of the stria terminalis of the rat. Brain Res 579: 321-326.

Jennings JH, Rizzi G, Stamatakis AM, Ung RL, Stuber GD (2013). The inhibitory circuit architecture of the lateral hypothalamus orchestrates feeding. Science 341: 1517-1521.

Kalin NH, Shelton SE, Fox AS, Oakes TR, Davidson RJ (2005). Brain regions associated with the expression and contextual regulation of anxiety in primates. Biol Psychiatry 58: 796-804.

Kessler RC, Berglund P, Demler O, Jin R, Walters EE (2005). Lifetime prevalence and age-of-onset distributions' of DSM-IV disorders in the national comorbidity survey replication. Arch Gen Psychiatry 62: 593-602.

Kozicz T, Vigh S, Arimura A (1997). Axon terminals containing PACAP- and VIP-immunoreactivity form synapses with CRFimmunoreactive neurons in the dorsolateral division of the bed nucleus of the stria terminalis in the rat. Brain Res 767: 109-119.

Kozicz T, Vigh S, Arimura A (1998). Immunohistochemical evidence for PACAP and VIP interaction with met-enkephalin and CRF containing neurons in the bed nucleus of the stria terminalis. Ann N Y Acad Sci 865: 523-528.

Krahn DD, Gosnell BA, Majchrzak MJ (1990). The anorectic effects of $\mathrm{CRH}$ and restraint stress decrease with repeated exposures. Biol Psychiatry 27: 1094-1102.

Krawczyk M, Sharma R, Mason X, Debacker J, Jones AA, Dumont EC (2011). A switch in the neuromodulatory effects of dopamine in the oval bed nucleus of the stria terminalis associated with cocaine self-administration in rats. J Neurosci 31: 8928-8935.

Lim MM, Tsivkovskaia NO, Bai Y, Young LJ, Ryabinin AE (2006). Distribution of corticotropin-releasing factor and urocortin 1 in the vole brain. Brain Behav Evol 68: 229-240.

Marti O, Armario A (1997). Influence of regularity of exposure to chronic stress on the pattern of habituation of pituitary-adrenal hormones, prolactin and glucose. Stress 1: 179-189.

Marti O, Marti J, Armario A (1994). Effects of chronic stress on food intake in rats: influence of stressor intensity and duration of daily exposure. Physiol Behav 55: 747-753.

Masuo Y, Suzuki N, Matsumoto H, Tokito F, Matsumoto Y, Tsuda $\mathrm{M}$ et al (1993). Regional distribution of pituitary adenylate cyclase activating polypeptide (PACAP) in the rat central nervous system as determined by sandwich-enzyme immunoassay. Brain Res 602: 57-63.

Matsuda K, Maruyama K, Miura T, Uchiyama M, Shioda S (2005a). Anorexigenic action of pituitary adenylate cyclase-activating polypeptide (PACAP) in the goldfish: feeding-induced changes in the expression of mRNAs for PACAP and its receptors in the brain, and locomotor response to central injection. Neurosci Lett 386: 9-13. 
Matsuda K, Maruyama K, Nakamachi T, Miura T, Uchiyama M, Shioda S (2005b). Inhibitory effects of pituitary adenylate cyclase-activating polypeptide (PACAP) and vasoactive intestinal peptide (VIP) on food intake in the goldfish, Carassius auratus. Peptides 26: 1611-1616.

McLean CP, Asnaani A, Litz BT, Hofmann SG (2011). Gender differences in anxiety disorders: prevalence, course of illness, comorbidity and burden of illness. J Psychiatr Res 45: 1027-1035.

Mertens I, Husson SJ, Janssen T, Lindemans M, Schoofs L (2007). PACAP and PDF signaling in the regulation of mammalian and insect circadian rhythms. Peptides 28: 1775-1783.

Michopoulos V, Higgins M, Toufexis D, Wilson ME (2012). Social subordination produces distinct stress-related phenotypes in female rhesus monkeys. Psychoneuroendocrinology 37: 1071-1085.

Mizuno Y, Kondo K, Terashima Y, Arima H, Murase T, Oiso Y (1998). Anorectic effect of pituitary adenylate cyclase activating polypeptide (PACAP) in rats: lack of evidence for involvement of hypothalamic neuropeptide gene expression. J Neuroendocrinol 10: 611-616.

Morley JE, Horowitz M, Morley PM, Flood JF (1992). Pituitary adenylate cyclase activating polypeptide (PACAP) reduces food intake in mice. Peptides 13: 1133-1135.

Mounien L, Do Rego JC, Bizet P, Boutelet I, Gourcerol G, Fournier A et al (2009). Pituitary adenylate cyclase-activating polypeptide inhibits food intake in mice through activation of the hypothalamic melanocortin system. Neuropsychopharmacology 34: 424-435.

Pego JM, Morgado P, Pinto LG, Cerqueira JJ, Almeida OFX, Sousa N (2008). Dissociation of the morphological correlates of stressinduced anxiety and fear. Eur J Neurosci 27: 1503-1516.

Piggins HD, Stamp JA, Burns J, Rusak B, Semba K (1996). Distribution of pituitary adenylate cyclase activating polypeptide (PACAP) immunoreactivity in the hypothalamus and extended amygdala of the rat. J Comp Neurol 376: 278-294.

Radley JJ, Gosselink KL, Sawchenko PE (2009). A discrete GABAergic relay mediates medial prefrontal cortical inhibition of the neuroendocrine stress response. J Neurosci 29: 7330-7340.

Radley JJ, Sawchenko PE (2011). A common substrate for prefrontal and hippocampal inhibition of the neuroendocrine stress response. J Neurosci 31: 9683-9695.

Resch JM, Maunze B, Gerhardt AK, Magnuson SK, Phillips KA, Choi S (2013). Intrahypothalamic pituitary adenylate cyclaseactivating polypeptide regulates energy balance via site-specific actions on feeding and metabolism. Am J Physiol Endocrinol Metab 305: E1452-E1463.

Ressler KJ, Mercer KB, Bradley B, Jovanovic T, Mahan A, Kerley K et al (2011). Post-traumatic stress disorder is associated with PACAP and the PAC1 receptor. Nature 470: 492-497.

Richard S, Martinez-Garcia F, Lanuza E, Davies DC (2004). Distribution of corticotropin-releasing factor-immunoreactive neurons in the central nervous system of the domestic chicken and Japanese quail. J Comp Neurol 469: 559-580.

Roman CW, Lezak KR, Kocho-Schellenberg M, Garret MA, Braas $\mathrm{K}$, May V et al (2012). Excitotoxic lesions of the bed nucleus of the stria terminalis (BNST) attenuate the effects of repeated stress on weight gain: evidence for the recruitment of BNST activity by repeated, but not acute, stress. Behav Brain Res 227: 300-304.

Shioda S, Shuto Y, Somogyvari-Vigh A, Legradi G, Onda H, Coy $\mathrm{DH}$ et al (1997). Localization and gene expression of the receptor for pituitary adenylate cyclase-activating polypeptide in the rat brain. Neurosci Res 28: 345-354.

Shughrue PJ, Lane MV, Merchenthaler I (1997). Comparative distribution of estrogen receptor-alpha and -beta mRNA in the rat central nervous system. J Comp Neurol 388: 507-525.

Simerly RB (1993). Distribution and regulation of steroid hormone receptor gene expression in the central nervous system. Adv Neurol 59: 207-226.

Somerville LH, Whalen PJ, Kelley WM (2010). Human bed nucleus of the stria terminalis indexes hypervigilant threat monitoring. Biol Psychiatry 68: 416-424.

Straube T, Mentzel HJ, Miltner WHR (2007). Waiting for spiders: brain activation during anticipatory anxiety in spider phobics. Neuroimage 37: 1427-1436.

Strom JO, Theodorsson E, Theodorsson A (2008). Order of magnitude differences between methods for maintaining physiological 17beta-oestradiol concentrations in ovariectomized rats. Scand J Clin Lab Invest 68: 814-822.

Stroth N, Holighaus Y, Ait-Ali D, Eiden LE (2011). PACAP: a master regulator of neuroendocrine stress circuits and the cellular stress response. Ann N Y Acad Sci 1220: 49-59.

Tachibana T, Saito S, Tomonaga S, Takagi T, Saito ES, Boswell T et al (2003a). Intracerebroventricular injection of vasoactive intestinal peptide and pituitary adenylate cyclase-activating polypeptide inhibits feeding in chicks. Neurosci Lett 339: 203-206.

Tachibana T, Tomonaga S, Oikawa D, Saito S, Takagi T, Saito ES et al (2003b). Pituitary adenylate cyclase activating polypeptide and vasoactive intestinal peptide inhibit feeding in the chick brain by different mechanisms. Neurosci Lett 348: $25-28$.

Turner SW, Wen C, Li M, Fraser TB, Whitworth JA (1998). Adrenocorticotrophin dose-response relationships in the rat: haemodynamic, metabolic and hormonal effects. J Hypertens 16: 593-600.

Valassi E, Scacchi M, Cavagnini F (2008). Neuroendocrine control of food intake. Nutr Metab Cardiovasc Dis 18: 158-168.

Vyas A, Bernal S, Chattarji S (2003). Effects of chronic stress on dendritic arborization in the central and extended amygdala. Brain Res 965: 290-294.

Waddell J, Morris RW, Bouton ME (2006). Effects of bed nucleus of the stria terminalis lesions on conditioned anxiety: aversive conditioning with long-duration conditional stimuli and reinstatement of extinguished fear. Behav Neurosci 120: 324-336.

Walker DL, Toufexis DJ, Davis M (2003). Role of the bed nucleus of the stria terminalis versus the amygdala in fear, stress, and anxiety. Eur J Pharmacol 463: 199-216. 